\title{
A EMERGÊNCIA DA SUBJETIVIDADE NO JORNAL DO CAPS, 0 TRABALHO DO ASSISTENTE SOCIAL E AS HISTÓRIAS DE VIDA
}

THE EMERGENCY OF SUBJECTIVITY IN THE CAPS JOURNAL, THE WORK OF THE SOCIAL ASSISTANT AND THE LIFE STORIES

Sabrina Regina Fiorelli', Fernanda Nunes da Rosa Mangini²

RECEBIDO EM: 05/07/2019 | ACEITO EM: 09/07/2019

DOI: $10.5902 / 2317175838908$

O Jornal do CAPS é fruto de um projeto de intervenção realizado no âmbito do Centro de Atenção Psicossocial, Álcool e outras drogas (CAPS Ad II - Caminhos do Sol) no município de Santa Maria/RS. A proposta surgiu a partir da ambiência e do contato com os usuários do serviço, os quais demandavam espaços de atenção e escuta às suas necessidades. Ou seja, havia uma expectativa, por parte dos usuários que permaneciam durante um longo tempo no serviço (oficinas, consultas, grupos) de ter um espaço de reconhecimento dos seus processos subjetivos, parti das histórias de vida.

O grupo Jornal do CAPS já existia desde 2014 na instituição, mas foi reestruturado sob o enfoque do Serviço Social na perspectiva do resgate das histórias de vida desses usuários cujo discurso era reduzido e, por diversas vezes, parecia rechaçado, possivelmente em função dos profissionais que ali atuavam já conhecerem, de trás para frente, as histórias de vida de cada um deles.

Um dos principais desafios dos profissionais de saúde mental é não naturalizar as expressões de sofrimento que cotidianamente se defrontam nos serviços. Há que se promover espaços de acolhida, atenção humanizada, observação e escuta sensível, na direção do reconhecimento, reflexão e auto-expressão dos usuários, especialmente dos seus sentimentos e conquistas.

A nova roupagem do grupo Jornal do CAPS estava pautada em uma proposta metodológica diferenciada, para abordar as expressões da questão social, como um espaço coletivo e criativo de trocas profícuas de experiências e relatos de vivências desses sujeitos, por meio do qual, o/a Assistente Social, buscou potencializar os movimentos de garantia de direitos, incentivando a emancipação social desses usuários.

Assim, o projeto Jornal do CAPS foi construído a partir das necessidades dos usuários por um lugar de fala, de expressão legítima, de manifestação de suas concepções, de seus valores e sentimentos em relação a si e ao mundo. Essa captura se deu através da história de vida, como uma ferramenta que contribui para uma análise das complexidades socioeconômicas e culturais que os usuários em sofrimento psíquico se defrontaram e se deparam na atualidade.

1 Assistente Social, graduada pela Universidade Federal de Santa Maria (2018). Atualmente integrante do Grupo de estudos, pesquisa e extensão em Tecnologia, Serviço Social e Sociedade (GETECSS), coordenado pela Profa. Dra. Fernanda Nunes da Rosa Mangini.

2 Graduada em Serviço Social (2007). Possui Mestrado em Educação (2010) e Serviço Social (2011). Doutora pelo Programa de Pós-graduação em 
O principal objetivo do projeto era construir um jornal por meio do qual os usuários pudessem expor suas histórias de vida, com a finalidade de promover o autorreconhecimento, a expressão e a reflexão sobre suas trajetórias, sob a perspectiva da reabilitação psicossocial, possibilitando também identificar possíveis demandas para a intervenção da equipe multidisciplinar no Plano Terapêutico Singular (PTS). A construção do jornal estava pautada na formulação, apresentação, escolha e configuração do que fora dito e escrito no âmbito das atividades coletivas.

Nesse sentido, de acordo com Martinelli (1999), "ao se reconhecer como sujeito produtor e reprodutor de significados o indivíduo está participando da história, está fazendo o relato de sua própria participação e reflexionando sobre sua própria vida, sobre sua participação na história pessoal e social". (MARTINELLI, 1999, p. 89).

A elaboração do jornal possibilitou a emergência de posições subjetivas na organização das narrativas, especialmente, a partir das escolhas dos sujeitos sobre o conteúdo que aparece na primeira página, a disposição dos textos e a organização do interior do jornal e, assim, firmando acordos, elegendo as histórias que o compuseram, definindo a quantidade de histórias e quais ficariam de fora da edição. Para Zanotti (2010) um jornal apresenta um uso social mais direto - de informação, de narrar fatos e histórias do cotidiano. Ao mesmo tempo, um jornal tem legitimidade social e a função de aproximar o estranho do comum, do que pode ser dito, contado e comentado.

O CAPS Ad II - Caminhos do Sol, atualmente, se propõe a atender as necessidades e demandas de aproximadamente 300 (ativos) usuários, com transtornos decorrentes do uso compulsivo e abusivo de substâncias psicoativas (dependência química). Para tanto, desenvolve cerca de 15 grupos sob a atenção multifatorial (bio-psico e socioeconômica) do trabalho qualificado da equipe multidisciplinar.

A dificuldade de adesão e permanência e a recusa ao tratamento por parte dos usuários é uma realidade recorrente na instituição. No processo de realização das reuniões semanais do CAPS Ad, os profissionais que realizam e ministram grupos e oficinas na instituição relatam que tem sido cada vez mais perceptível o processo de recusa na adesão do tratamento, bem como a sua continuidade desde 2014, realidade que precisa e merece ser investigada.

Para conseguir dar início as atividades propostas pelo grupo Jornal do CAPS foi preciso juntar esforços com os demais profissionais no CAPS Ad, tendo em vista a dificuldade em fazer com que os usuários participassem desse grupo, que anteriormente existia sob outros moldes. Assim, foram dispostos cartazes pelos corredores do CAPS Ad, como divulgação para o grupo, bem como, disponibilizadas fichas de inscrição na sala de espera. Também foram realocados alguns usuários participantes de outros grupos para o Jornal do CAPS.

O desenvolvimento do grupo Jornal do CAPS e os recursos temáticos fizeram parte de uma construção coletiva, na qual os cinco usuários que frequentaram o grupo assiduamente, foram protagonistas. Nessa direção, durante os 
encontros, iam surgindo questões a serem trabalhadas nas próximas semanas e, assim, com a participação de todos, foram se estabelecendo temas a serem debatidos, as histórias que deveriam ser compartilhadas de forma escrita e, como, se daria o processo de formulação e formatação da versão final do jornal.

Os processos que envolveram a construção e a concretização das atividades do grupo do Jornal do CAPS, ocorreram entre março e agosto de 2018, sendo realizados ao longo de 09 encontros.

No primeiro encontro, foram trabalhados os papeis que cada usuário imagina ocupar na sociedade. Essa discussão teve o respaldo do texto de Nara Rubia Ribeiro "A desumanização do Humano", o qual foi escolhido pelos usuários para composição do jornal (p. 2). O texto traz uma relação de determinadas situações que a autora presencia, como a desvalorização ou negligência aos Direitos Humanos, fazendo uma crítica à sociedade a qual ela pertence que subsidia e pratica a desumanização do ser humano.

A partir do debate desse texto, emergiram posições subjetivas em relação à política e à religião, que motivaram o encontro seguinte, uma vez que no decorrer do processo de realização das atividades os usuários divergiram muito e, constantemente, demonstrando possuírem visões de homem e de mundo distintas, mesmo fazendo parte de processos e vivências parecidos.

Diante disso, foi realizada a Dinâmica das Diferenças que teve como proposta a elaboração de uma representação ilustrativa. Os desenhos e os procedimentos de elaboração estão indicados no jornal (p. 3). A dinâmica conduz a reflexão de que todos nós somos iguais, porém não necessariamente veremos as mesmas situações de forma igual. O que nos difere é a diversidade, temos visões de mundo diferentes um do outro e, por isso, devemos respeitar uns aos outros e, principalmente, às opiniões dos outros.

Foi a partir do sexto encontro que começaram a ser organizadas a seções do jornal a ser impresso. Nesse encontro foram abordados diversos assuntos e os usuários escolheram a temática da reciclagem para compor a seção de curiosidades do jornal juntamente com o filme Into The Wild (Na natureza selvagem), dirigido por Sean Penn, apresentado e debatido no terceiro encontro (p. 5-6).

A temática da reciclagem foi escolhida porque a maioria dos usuários se encontrava em situação de rua e vivia da renda obtida através da coleta e reciclagem do lixo. A coleta do lixo e sua reciclagem é uma forma de trabalho que constitui a identidade daqueles sujeitos, os quais encontraram no jornal uma forma de expressão do seu ser, especialmente da centralidade do trabalho nas suas vidas e dos descontentamentos com o modo que a sociedade descarta o lixo e trata aqueles que vivem dessa modalidade de trabalho como seres indesejáveis e supostamente invisíveis.

Os usuários também prepararam versões escritas de suas trajetórias de vida para compor o jornal, os textos poderiam ter o teor que lhes interessasse escrever naquele determinado momento (p. 8-9). Além disso, os usuários indicaram a programação das oficinas do CAPS Ad para compor o Jornal (p. 4). 
O último dia de realização das atividades do grupo do Jornal do CAPS se juntou à festa Junina, que foi promovida pelo CAPS Ad II- Caminhos do Sol. Nesse encontro, aproveitamos para entregar os exemplares dos jornais impressos para os participantes do grupo. Por fim, foi escolhida uma poesia de autoria de um dos usuários do CAPS Ad como forma de homenagem e lembrança ao usuário que faleceu em uma data próxima ao penúltimo encontro do grupo (p. 7).

A dinâmica de construção do jornal permitiu compreender que a subjetividade dos usuários é tanto produto como produtora das transformações que acometem a sociedade. Nas palavras de Gentilli (2013):

[...] a necessidade de se considerar indivíduo e sociedade como categorias que tomam parte de uma mesma realidade ontogenética, onde cada indivíduo humano é, ao mesmo tempo, o indivíduo sócio histórico, sem que ninguém possa substituí-lo nas relações sociais. Isso significa dizer que as formas subjetivas de cada ser são inferidas - porque nelas constituídas - das relações sociais e mesmo as situações mais íntimas do ser possuem inscrição na cultura, na ciência, na política, na economia. (GENTILLI, 2013, p. 316).

Essa dinâmica também possibilitou a apreensão dos significados que a sociedade, engendrada pelo modo de produção capitalista, produz, interfere e captura os sujeitos de uma maneira muito agressiva, dificultando que esses indivíduos reconheçam e vislumbrem um novo direcionamento para suas vidas.

A emersão desses processos se tornou possível à identificação de que os usuários apresentavam indiretamente no seu discurso e, até mesmo na sua forma de se colocar diante do profissional ou da família, uma certa timidez, desconhecimento de si e de suas atitudes. Em outras palavras, sentiam-se envergonhados, despotencializados, despreparados, destituídos e irreconhecíveis como seres dotados de direitos, culpabilizando-se, de forma extremista, às questões que se relacionam ao seu processo de dependência química.

As trocas de experiências, possibilitadas pela construção do jornal, estimularam o desenvolvimento das capacidades de reflexão, reconhecimento e auto-expressão, permitindo situar o indivíduo no seu meio, desmistificando e desconstruindo preconceitos. O Jornal, possibilitou um lugar de fala, de expressão do que é vivido cotidianamente em silêncio, como sofrimento e rebeldia. Assim, foi só o despertar para trocas sociais mais abrangentes que dependem da reconstrução e afirmação da identidade, como sujeitos que pertencem a um grupo e a uma classe social.

De acordo com Lane (2006) somente a partir do momento que o sujeito encontra as razões históricas da sociedade e do grupo social ao qual pertence que é possível reconstruir a subjetividade. É preciso, segundo ela, refletir sobre os papeis que desempenhamos e suas questões históricas. O processo grupal permite, segundo Lane (2006, p. 22), "reconhecer quem sou eu enquanto indivíduo, enquanto integrante de um grupo social, a partir das relações do meu ser social. Isso só será possível no momento em que tenho o 'outro' como referência". 
A dependência química é um problema complexo que tem dimensões bio-psico-sociais. Em uma realidade extremamente desigual, como a brasileira, a dimensão social, é muito significativa na dependência química, que incide diretamente na constituição da subjetividade. A emersão dessa subjetividade está expressa no Jornal do CAPS.

\section{Referências bibliográficas}

MARTINELLI, M. L. Pesquisa qualitativa: um instigante desafio. São Paulo: Editora Veras, 1999.

LANE, S. T. M.O que é psicologia social. São Paulo: Brasiliense, 2006. Disponível em: < https://edisciplinas.usp. br/pluginfile.php/139985/mod_resource/content/1/O-que-\%C3\%A9-Psicologia-Social.pdf>. Acesso em: 04.jul.2019.

GENTILLI, R. M. L. Sociabilidade e Subjetividade: aproximações para o Serviço Social. Textos \& Contextos, v. 12, n. 2, p. 312 - 324, jul./dez. 2013, Porto Alegre, RS. Disponível em: <http://revistaseletronicas.pucrs.br/ojs/ index.php/fass/article/view/14272/10742>. Acesso em: 04.jul.2019.LASKOSKI, Lorena Maria; NATIVIDADE, Jean Carlos; HUTZ, Claudio Simon. Development of Instruments to Assess Shame and Guilt in Adolescents: Empirical Differences Between the Constructs. Ribeirão Preto, 2013. 